\title{
Pengembangan Konsep Pembelajaran Literasi Digital Berbasis Media E-Learning Pada Mata Pelajaran PJOK di SMA Kota Yogyakarta
}

\author{
Muhammad Imam Rahmatullah \\ Universitas Negeri Yogyakarta \\ Muhammadimamrahmatullah@gmail.com
}

\begin{abstract}
Abstrak
Penelitian ini bertujuan untuk mengetahui kelayakan produk software sebagai media pembelajaran e-learning mata pelejaran PJOK di SMA Kota Yogyakartadan sebagai media alternatif dalam pelaksanaan literasi olahraga. Metode yang digunakan adalah $\mathrm{R} \& \mathrm{D}$ (research and development) dengan menggunakan penilaian ahli media serta uji coba coba skala kecil dan uji coba skala besar. Subjek penelitian yang digunakan adalah 30 responden untuk uji coba skala kecil dan 60 responden untuk uji coba skala besar di SMA Kota Yogyakarta. Hasil dari penelitian pada uji coba skala kecil adalah penilaian produk pada aspek pemograman memiliki rerata skor sebesar 2.97 dan dalam skala (1-100) nilainya 74,22 sehingga masuk ke dalam kriteria baik dan hasil uji coba skala besar memiliki penilalian produk aspek pemogramanan sebesar 3,08 dan dalam skala (1-100) nilainya 77,02 sehingga masuk dalam kriteria baik. Berdasarkan hasil penilaian ahli media pemograman, uji coba skala kecil dan uji coba skala besar, produk software ini layak digunakan sebagai media pembelajaran PJOK di tingkat SMA.
\end{abstract}

Kata kunci: Literasi, Media, e-learning, PJOK

Abstract

This research aimed to find out the appropriateness of software product as e-learning media in the Physical Sport Education and Health subject in Senior High School at Yogyakarta city. Besides, the product also became the alternative media in the learning process of sport literacy. This research used Research and Development method by using expert judgment of media and try out (small and big scale). The subject of the research contains of 30 respondents for small try out and 60 respondents for final try out in the senior high school at Yogyakarta city. The results of the research based on the small try out found out that the product evaluation of program aspects had the average of 2.97, and the score showed 74.22 in the (1-100) scale. It meant that the product included in good category. Moreover, the final try out found out that the product evaluation of program aspects had the average of 3.08, and the score showed 77.02 in the (1-100) scale. It also included in good category. Based on the evaluation of media expert of program, small try out, and final try out the software product was appropriate to be implemented as the learning media in Physical Sport Education and Health subject for senior high school level.

Key word: Literacy, Media, e-learning, Physical Sport Education and Health 


\section{PENDAHULUAN}

PJOK (pendidikan jasmani olahrga dan kesehatan) merupakan suatu cabang ilmu yang mempelajari tentang aktivitas gerak melalui media olahraga, sedangkan menurut Syarifuddin dalam Santoso (2009) PJOK merupakan aktivitas jasmani yang dirancang dan disusun secara sistematik untuk merangsang pertumbuhan dan perkembangan serta pembentukan karakter dalam rangka mencapai tujuan pendidikan.

PJOK sebagai suatu cabang ilmu yang paling substansi dalam mengembangkan wawasan keolahragaan di sektor pendidikan formal memiliki peran dalam menjalankan nilai-nilai olahraga. Salah satu cara untuk menjalankan nilainilai olahraga yaitu melalui literasi. Studi terbaru menunjukkan bahwa kurikulum PJOK harus melibatkan pendekatan literasi fisik serta keterampilan gerakan dasar. Jadi melek fisik adalah tujuan yang sangat penting dari pendidikan jasmani. Pemahaman terhadap literasi fisik dapat memudahkan siswa dalam proses pembelajaran PJOK (Basoglu, 2018). Melek fisik disini mempunyai arti megetahui hal-hal yang berhubungan dengan pengetahuan literasi fisik. Pengetahuan literasi fisik salah satunya didapat dari kemampuan memperoleh informasi dari media digital.Oleh karena itu, kemampuan dalam literasi digital sangat diperlukan, karena arus informasi yang semakin berkembang terutama di sektor pendidikan formal. Datangnya era keterbukaan informasi dan media yang semakin berkembang secara otomatis akan mengubah perilaku dalam berinteraksi.

Perubahan perilaku ini seiring dengan kemunculan komputer, internet dan gawai. Bahkan istilah literasi juga mengalami perubahan dan mengalami perkembangan (Noh: 2016). Sejalan dengan Noh, Abidin (2017) menjelaskan literasi di era pendidikan kontemporer saat ini mengalami pergeseran makna dan diperluas ke dalam empat jenis elemen literasi yaitu literasi visual, auditori, dan spasial. Keempat elemen literasi tersebut erat kaitannya dengan literasi digital.

Gilster, yang pertama kali mengenalkan isitilah literasi digital (digital literacy) mengemukakan literasi digital adalah kemampuan menggunakan teknologi dan informasi dari piranti digital secara efektif dan efisien dalam berbagai konteks seperti, akademik, karier dan kehidupan sehari-hari (Gillster: 1997). Pendapat Gilster tersebut seolah-olah menyederhanakan bahwasanya media dapat dipergunakan untuk mempermudah kinerja manusia dalam melakukan kegiatan.

Literasi digital dalam pembelajaran PJOK dapat dihadirkan melalui konsep pembelajaran e-learning. Pembelajaran elearning pada dasarnya bertujuan untuk memudahkan guru dan siswa melakukan pembelajaran jarak jauh. Hal ini juga didasarkan pada kurang fleksibelnya media dan buku cetak dalam mengikuti perkembangan zaman (Wahyuningsih, 2017). E-learning pada hakikatnya juga merupakan pembelajaran dua cabang yaitu offline dan online. Offline e-learning pada dasarnya tidak menggunakan jaringan internet dalam pelaksanannya, berbeda halnya dengan online learning yang mesti menggunakan jaringan sebagai syarat utama penggunannya (Wahyuningsih, 2017: 4-5). Oleh karena itu, penggunaann media offline dan online harus digunakan dalam proses pembelajaran di sekolah untuk mengikuti perkembangan zaman. Oleh karena itu, untuk memudahkan proses pembelajaran muncullah inovasi media pembelajaran berupa software.

Berkaitan dengan hal ini, Oleh karena itu, sistem informasi sangat dibutuhkan untuk menunjang pembelajaran yang berkaitan dengan olahraga. Sistem informasi tersebut dapat diintegrasikan melalui media pembelajaran software. Sebelumnya, penelitian yang 
menggunakan media sebagai proses pembelajaran e-learning juga pernah dilakukan oleh Beny Widiantoro dan Lusiana Rakhmawati dengan judul "Pengembangan Media Pembelajaran ELearning Berbasis Schoology pada Kompetensi Dasar Memahami Model Atom Bahan Semi Konduktor di SMKN 1 Jetis Mojokerto, hasil dari penelitian ini secara umum mendapat respons positif dari siswa dan dinyatakan sangat layak diterapkan di sekolah (Widiantoro, B., \& Rakhmawati, L: 2015). Sejalan dengan Widiantoro dan Rakhmawati, penelitian pengembangan juga pernah dilakukan oleh Lubis (2015) dengan judul "Pengembangan Media Pembelajaran Kimia Berbasis Android untuk Meningkatkan Motivasi Belajar dan Prestasi Kognitif Peserta didik Sekolah Menengah Atas. Hasil dari penelitian tersebut menunjukkan pembelajaran menggunakan media elektronik memiliki karakteristik, yaitu visualisasi menarik, praktis, dan fleksibel. Sejalan dengan Lubis penelitian. Dari kedua penelitian yang relevan di atas, penelitian ini akan difokuskan pembuatan media pembelajaran PJOK berbasis e-learning di SMA Kota Yogyakarta. Hal ini didasari oleh masih terfokusnya materi pembelajaran PJOK dari LKS (lembar kerja Siswa). Dengan adanya media pembelajaran berbentuk software ini, diharapkan dapat menjadi sumber alternatif pembelajaran bagi guru dan siswa di SMA Kota Yogyakarta.

\section{METODE}

Penelitian pengembangan ada beberapa langkah yang bisa dilakukan. Langkah-langkah penelitian pengembangan tersebut adalah sebagai berikut: (1) pengumpulan, (2) perencanaan, (3) pengembangan produk awal, (4) uji coba, (5) revisi untuk menyusun produk utama, (6) uji coba lapangan, (7) revisi untuk menyusun produk, (8) uji coba produk operasional, (9) revisi produk, (10) diseminasi dan implementasi produk (Borg, 2007: 589-593). Untuk mengefisiensi waktu dan biaya, prosedur penelitian diringkas menjadi empat langkah sebagai berikut.

\section{Define}

Berisi kegiatan untuk menetapkan produk yang akan dikembangkan beserta spesifikasinya. Tahap ini merupakan kegiatan analisis kebutuhan dan kajian literaturyang relevan dengan tema penelitian.

\section{Design}

Tahap design penelitian betujuan untuk membuat produk awal rancangan (prototype) software literasi digital. Pengembangan software literasi digital dilakukan dengan membuat kerangka konseptual sesuai dengan analisis kurikulum dan materi. Tahapan design dilakukan melalui dua pokok tahapan, yaitu perencanaan dan perancangan.

\section{Development}

Thiagarajan membagi tahap pengembangan dalam dua langkah kegiatan yaitu expert appraisal, dan developmental testing. (a) Expert Appraisal.Tahap expert appraisal berupa proses untuk menilai rancangan produk software literasi digital atas dasar rasional ahli. Produk software literasi digital yang disusun peneliti lalu divalidasi oleh ahli (judgement expert). Selanjutnya dilakukan revisi produk atas saran-saran yang diberikan untuk memperbaiki produk yang telah disusun. (b) Developmental Testing. Tahap ini merupakan kegiatan uji rancangan produk pada sasaran subjek yang sesungguhnya. Jika tahap expert appraisal dilakukan penilaian atas dasar rasional ahli, pada tahap developmental testing penilaian dilakukan atas dasar data empiris, yaitu hasil uji coba instrumen pada subjek nyata di lapangan. Tahap developmental testing dilakukan melalui dua tahapan, yaitu uji coba skala kecil dan uji coba skala besar, (c) Uji Coba Skala Kecil. Uji coba ini menggunakan 
responden sebanyak 30 Siswa SMA IT Abu Bakar Yogyakarta. Uji coba skala kecil ini menghimpun data respons pengguna sebagai dasar perbaikan produk selanjutnya. Hasil penilaian uji coba skala kecil ini juga digunakan untuk menganalisis reliabilitas instrumen, yaitu reliabilitas antarpenilai yang melibatkan rater dan siswa. (d) Uji Coba Skala Besar. Uji coba ini menggunakan responden sebanyak 60 siswa yang terdiri atas 30 siswa SMAN 3 Yogyakarta dan 30 sisa SMAN 7 Yogyakarta. Uji coba ini dilakukan pada kelas yang sedang menempuh materi pembelajaran PJOK. Sama halnya dengan uji coba skala kecil, uji coba skala besar juga dilaksanakan untuk menganalisis reliabilitas instrumen, yaitu interrater reliability yang melibatkan rater dan siswa.

\begin{tabular}{|c|c|c|}
\hline Aspek yang Dinilai & $\begin{array}{l}\text { Rerata } \\
\text { Penilaian }\end{array}$ & Kriteria \\
\hline \multicolumn{3}{|c|}{$\begin{array}{lc} & \text { Aspek Isi }\end{array}$} \\
\hline $\begin{array}{l}\text { Kesesuaianindikatorsoaldengankompetensi } \\
\text { yang akandicapai. }\end{array}$ & 3,50 & Sangat Baik \\
\hline $\begin{array}{l}\text { Kesesuaianindikatorsoaldengan konsep } \\
\text { literasi digital. }\end{array}$ & 3,50 & Sangat Baik \\
\hline Konstruksi soal. & 3 & Baik \\
\hline \multicolumn{3}{|c|}{ Aspek Bahasa } \\
\hline Kebenaran penggunaan bahasa. & 3,50 & Sangat Baik \\
\hline $\begin{array}{l}\text { Ketepatan kalimat yang digunakan tidak } \\
\text { menimbulkan penafsiran. }\end{array}$ & 3 & Baik \\
\hline Rerata Keseluruhan & $\mathbf{3 , 3 0}$ & Sangat Baik \\
\hline
\end{tabular}

\section{Dissemination}

Diseminasi dalam penelitian dan pengembangan merupakan suatu kegiatan yang ditujukan kepada kelompok target atau individu agar mereka memperoloeh produk yang telah diuji untuk dimanfaatkan (Sugiyono, 2017: 28). Dalam penelitian ini tahap dissemination tidak dilaksanakan karena keterbatasan waktu dan biaya. Penelitian ini hanya sampai uji kelayakan produk.

\section{A. Uji Coba Instrumen}

Uji coba dimaksudkan untuk memperoleh data secara lengkap yang dapat digunakan sebagai bahan revisi produk. Aspek yang divalidasi dalam tahap uji model pengembangan ini meliputi beberapa hal sebagai berikut.

\section{Validasi Ahli Materi}

Produk yang dikembangkan divalidasi oleh 1 ahli materi sebelum diujicobakan kepada siswa. Validasi dari ahli berupa penilaian, komentar, dan saran perbaikan sangat diperlukan agar produk yang dikembangkan layak digunakan dan sesuai dengan yang dibutuhkan siswa.Validasinya juga meliputi validasi lembar penilaian produk. Setelah produk dinyatakan layak oleh ahli media, selanjutnya dilakukan uji coba instrumen yang nantinya akan digunakan sebagai alat evaluasi pada uji coba skala kecil (small group evaluation) dan uji coba skala besar (field trial). Uji instrumen dilakukan validasi isi berkaitan dengan kesesuaian intrumen dengan produk yang dihasilkan. Hasil uji validasi instrumen dapat dilihat pada Tabel 1 dibawah ini.

Tabel 1. Hasil uji validitas instrumen

Sumber: Olah data excell

Berdasarkan tabel di atas, validasi angket (intsrumen) dari ahli menyatakan bahwa instrumen angket sangat baik/sangat layak 
untuk digunakan baik dilihat dari aspek isi maupun aspek bahasa.

\section{Uji Validitas Instrumen}

Uji validitas menggunakan SPSS Statistics 17.0 for windows. Taraf signifikansi yang

yang ada pada butir yang dimaksud dengan skor total. Kriteria pengambilan keputusan untuk menentukan valid jika harga $r$ hitung sama dengan atau lebih besar dari harga $\mathrm{r}$ pada taraf signifikansi 5\%. Jika $\mathrm{r}$ hitung lebih kecil dari $\mathrm{r}$ pada taraf signifikansi $5 \%$, butir instrumen yang dimaksud tidak valid.Arikunto (2011: 87) menyatakan bahwa persyaratan bagi tes yaitu validitas dan reliabilitas sangat penting. Uji validitas instrumen dan reliabilitas ini perlu karena menyokong terbentuknya validitas. Sebuah digunakanadalah5\% dan nilai $\mathrm{r}=0,3$. Validitas butir diketahui dengan mengorelasi tes mungkin reliabel tetapi tidak valid. Sebaliknya sebuah tes valid biasanya reliabel. Dikatakan reliabel apabila memiliki nilai cronbach alpha > 0,6. Uji validitas dan reabilitas diberikan pada 30 responden di luar subjek penelitian. Instrumen tanggapan siswa terhadap produk pembelajaran software literasi digital berbasis media e-learning dalam penelitian ini berupa angket dengan jumlah pernyataan sebanyak 14. Hasilnya dapat dilihat pada Tabel 2 sebagai berikut.

Tabel 2. Butir validitas instrumen siswa

\section{ButirPernyataan Corrected Item Total Correlation Keterangan}

\begin{tabular}{ccc}
\hline Butir 1 & 0,733 & Valid \\
\hline Butir 2 & 0,479 & Valid \\
\hline Butir 3 & 0,511 & Valid \\
\hline Butir 4 & 0,762 & Valid \\
\hline Butir 5 & 0,350 & Valid \\
\hline Butir 6 & 0,574 & Valid \\
\hline Butir 7 & 0,361 & Valid \\
\hline Butir 8 & 0,480 & Valid \\
\hline Butir 9 & 0,333 & Valid \\
\hline Butir 10 & 0,401 & Valid \\
\hline Butir 11 & 0,714 & Valid \\
\hline Butir 12 & 0,557 & Valid \\
\hline Butir 13 & 0,500 & Valid \\
\hline Butir 14 & 0,316 & Valid \\
\hline
\end{tabular}

Sumber: Olah data SPSS

Berdasarkan table di atas dapat diambil kesimpulan bahwa semua pernyataan dalam angket valid. Pernyataan yang valid berjumlah 14 butir,. Selain hasil validitas, ditunjukkan juga hasil reliabilitas instrumen. Hasil perhitungan cronbach 
alpha yaitu 0,852 sehingga instrumen yang digunakan reliable.

\section{B. Teknik Analisa data}

Tanggapan ahli media pemograman dan siswa berupa data skor yang diperoleh melalui angket, dianalisis secara deskriptif kuantitatif dengan teknik persentase dan kategorisasi. Data yang diperoleh diubah menjadi data interval.

Tabel 3. Skor penilaian

\begin{tabular}{|c|c|}
\hline Skor & Makna \\
\hline 4 & $\begin{array}{l}\text { Unsur-unsur yang adadalampertanyaan/ pernyataantersebutsesuaidenganangka } \\
100 \% \text {. }\end{array}$ \\
\hline 3 & $\begin{array}{l}\text { Unsur -unsur yang adadalampertanyaan/ pernyataantersebutsesuaidenganangka } \\
80 \% \text {. }\end{array}$ \\
\hline 2 & $\begin{array}{l}\text { Unsur-unsur yang adadalampertanyaan/ pernyataantersebutsesuaidenganangka } \\
40 \% \text {. }\end{array}$ \\
\hline 1 & $\begin{array}{l}\text { Unsur-unsur yang adadalampertanyaan/ pernyataantersebutsesuaidenganangka } \\
20 \% \text {. }\end{array}$ \\
\hline
\end{tabular}

Sumber:(Sukardjo, 2006: 52)

Dalam angket diberikan lima pilihan untuk memberikan tanggapan tentang produk yang dikembangkan, yaitu sangat baik (5), baik (4), cukup (3), kurang (2), dan sangat kurang (1). Seandainya tanggapan siswa "sangat baik" pada suatu butir pertanyaan atau pernyataan, skor butir tersebut sebesar " 5 ", demikian seterusnya. Skor yang diperoleh kemudian dikonversikan menjadi data kuantitatif.
Kelayakan media pembelajaran berbantuan computer dari ahli materi dan media dinyatakan dengan angka berskala (1-5). Skor yang diperoleh kemudian dikonversikan menjadi data kualitatif skala lima, dengan menggunakan acuan rumus pendekatan PAP (penilaian acuan patokan) (Sukardjo, 2006: 52) sebagai berikut. Skor penilaian dapat dilihat pada Tabel 4 berikut ini.

Tabel 4. Penilaian acuan patokan(PAP)

\begin{tabular}{lll}
\hline Nilai & \multicolumn{1}{c}{ Skor } \\
\hline $\mathrm{A}$ & $\bar{x}_{i}+1,50 S B_{i}<\mathrm{X}$ \\
\hline $\mathrm{B}$ & $\bar{x}_{i}+0,50 S B_{i}<\mathrm{X} \leq$ & $\bar{x}_{i}+1,50 S B_{i}$ \\
\hline $\mathrm{C}$ & $\bar{x}_{i}-1,50 S B_{i}<\mathrm{X} \leq$ & $\bar{x}_{i}-0,50 S B_{i}$ \\
\hline $\mathrm{D}$ & $\mathrm{X} \leq$ & $\bar{x}_{i}-1,50 S B_{i}$ \\
\hline
\end{tabular}

Sumber: (Sukardjo, 2006: 52)

Berdasarkan rumus konversi skor pada skala 4 di atas, diperoleh pedoman konversi data sebagai berikut.

Tabel 5. Pedoman konversi data kuantitatif ke data kualitatif

Nilai Interval Perhitungan Kriteria
A
$X>3,25$
Sangat Baik/Sangat Layak 
B $\quad 2,75<X \leq 3,25$

Baik/Layak

\begin{tabular}{ccc}
\hline $\mathrm{D}$ & $1,75<\mathrm{X} \leq 2,75$ & Kurang/Kurang Layak \\
\hline $\mathrm{E}$ & $\mathrm{X} \leq 1,75$ & SangatKurang/Sangat tidak layak \\
\hline
\end{tabular}

Sumber: ( Sukardjo, 2006: 52)

Dalam penelitian ini, ditetapkan nilai kelayakan produk minimal kategori "baik", sebagai hasil penilaian baik dari ahli dan siswa. Jika hasil penilaian akhir (keseluruhan) pada aspek materi dan media yang dikembangkan dengan nilai minimal cukup baik oleh para ahli dan

\section{HASIL DAN PEMBAHASAN}

a. Validasi Ahli Media

Produk yang dikembangkan

divalidasi oleh 1 ahli media pemograman sebelum diujicobakan kepada siswa.

Tabel 7. Hasil validasi ahli media

\begin{tabular}{lcc}
\hline \multicolumn{1}{c}{ Aspek yang Dinilai } & Skor Penilaian & Kriteria \\
\hline $\begin{array}{l}\text { Tampilan keseluruhan } \\
\text { software menarik. }\end{array}$ & 4 & Sangat Baik \\
\hline $\begin{array}{l}\text { Penggunaan software mudah } \\
\text { diakses. }\end{array}$ & 3 & Baik \\
$\begin{array}{l}\text { Software memudahkan guru } \\
\text { dan siswa dalam proses belajar } \\
\text { mengajar. }\end{array}$ & 3 & Baik \\
\hline $\begin{array}{l}\text { Software berfungsi dengan } \\
\text { benar. }\end{array}$ & 4 & Sangat Baik \\
\hline $\begin{array}{l}\text { Ikon pada software sudah } \\
\text { sesuai dengan fungsinya. }\end{array}$ & 3 & Baik \\
\hline $\begin{array}{l}\text { Tata letak setiap icon } \text { mudah } \\
\text { dipahami. }\end{array}$ & 3 & Baik \\
\hline Jumlah & 20 & Sangat Baik \\
\hline Rata-rata & 3,33 &
\end{tabular}

Sumber: Olah data excell

Berdasarkan tabel di atas dapat dilihat bahwa aspek pembelajaran rerata skornya terletak pada rentang 2,75-3,25 sehingga masuk ke dalam kriteria sangat baik. Hasil penilaian ahli media pemograman menunjukkan bahwa produk yang siswa, produk pembelajaran software literasi digital berbasis media $e$ learninghasil pengembangan tersebut sudah dianggap layak digunakan oleh siswa sebagai bahan dan media pembelajaran.

Validasi dari ahli berupa penilaian, komentar, dan saran perbaikan sangat diperlukan agar produk yang dikembangkan layak digunakan dan sesuai dengan yang dibutuhkan siswa. 


\section{Aspek Kemudahan Mengakses}

\begin{tabular}{|c|c|c|c|}
\hline Membantu dalam proses pembelajaran PJOK. & 198 & 3,30 & $\begin{array}{c}\text { Sangat } \\
\text { Baik }\end{array}$ \\
\hline $\begin{array}{l}\text { Kemudahan akses software membuat motivasi belajar } \\
\text { meningkat. }\end{array}$ & 159 & 2,65 & $\begin{array}{c}\text { Kurang } \\
\text { Baik }\end{array}$ \\
\hline Keseluruhan & 357 & 2,98 & Baik \\
\hline \multicolumn{4}{|l|}{ Aspek Keaktifan } \\
\hline Aktif dalam proses pembelajaran PJOK. & 169 & 2,82 & Baik \\
\hline \multicolumn{4}{|c|}{ Aspek Pemahanan terhadap Produk } \\
\hline Pemahaman materi melalui aplikasi software. & 181 & 3,02 & Baik \\
\hline \multicolumn{4}{|l|}{$\begin{array}{l}\text { Aspek Keberanian } \\
\end{array}$} \\
\hline Keberanian dalam mengeluarkan argumentasi. & 184 & 3,07 & Baik \\
\hline \multicolumn{4}{|l|}{ Aspek Minat Belajar } \\
\hline $\begin{array}{l}\text { Ketertarikan terhadap mata pelajaran menggunakan aplikasi } \\
\text { software. }\end{array}$ & 190 & 3,17 & Baik \\
\hline Keinginan untuk berdiskusi dalam pelajaran. & 166 & 2,77 & Baik \\
\hline Keseluruhan & 356 & 2,97 & Baik \\
\hline Jumlah Total & 1247 & 74,22 & \\
\hline Rerata Total & 74,22 & 2,97 & Baik \\
\hline
\end{tabular}

Tabel 7. Hasil uji coba skala besar

\begin{tabular}{|c|c|c|c|}
\hline Aspek yang Dinilai & $\begin{array}{l}\text { Skor } \\
\text { Penil } \\
\text { aian }\end{array}$ & Rerata & Kriteria \\
\hline \multicolumn{4}{|c|}{ Aspek Kemudahan Mengakses } \\
\hline $\begin{array}{l}\text { Membantu dalam } \\
\text { proses pembelajaran } \\
\text { PJOK. }\end{array}$ & 394 & 3,28 & Sangat Baik \\
\hline $\begin{array}{l}\text { Kemudahan akses } \\
\text { software membuat } \\
\text { motivasi belajar } \\
\text { meningkat. }\end{array}$ & 363 & 3,02 & Baik \\
\hline Keseluruhan & 757 & 3,15 & Baik \\
\hline \multicolumn{4}{|c|}{ Aspek Keaktifan } \\
\hline $\begin{array}{l}\text { Aktif dalam proses } \\
\text { pembelajaran PJOK. }\end{array}$ & 364 & 3,03 & Baik \\
\hline \multicolumn{4}{|c|}{ Aspek Pemahanan terhadap Produk } \\
\hline
\end{tabular}




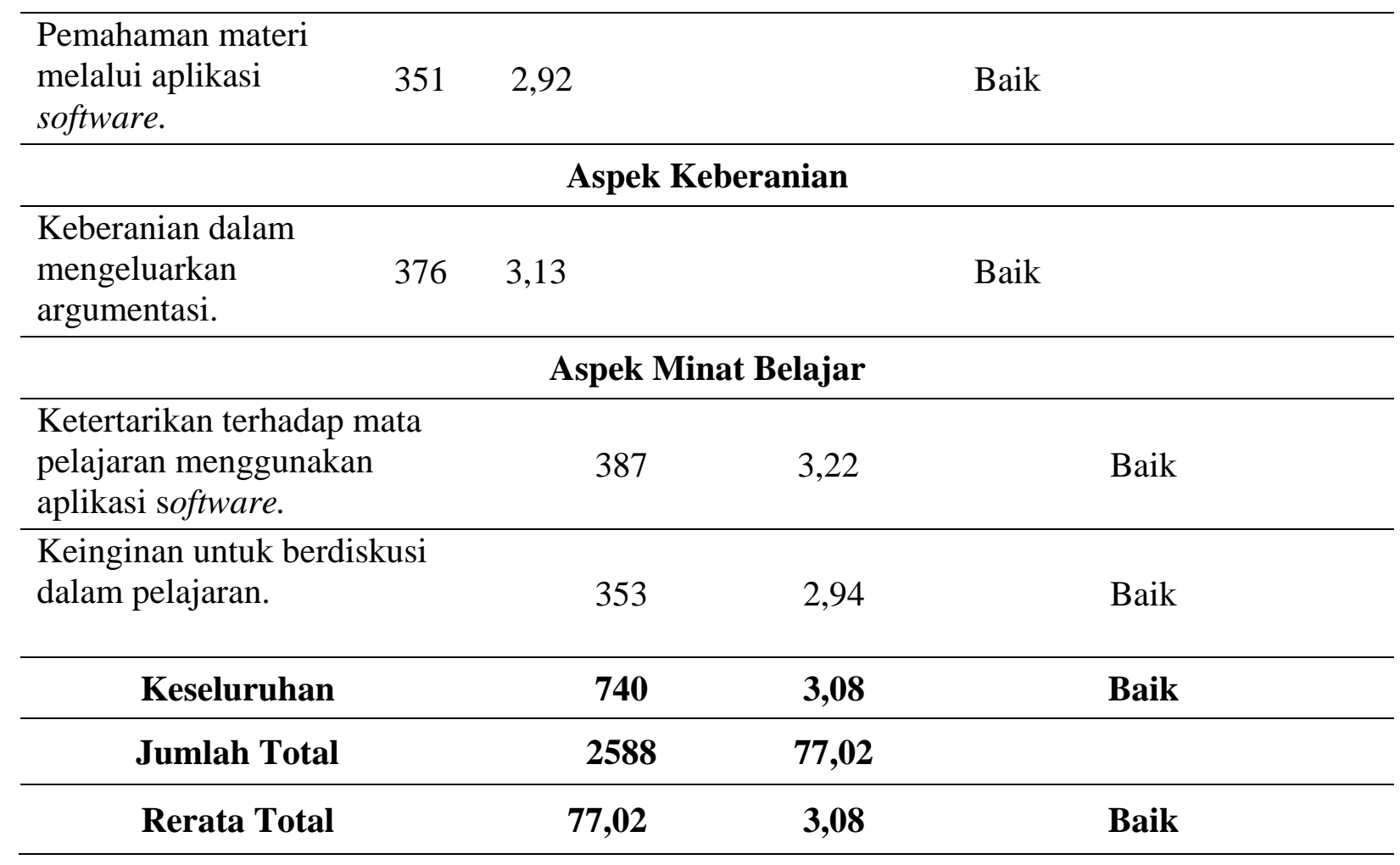

\section{d. Hasil Uji Coba Skala Kecil dan Uji Coba Skala besar.}

Penilaian produk pada aspek pemograman memiliki rerata skor sebesar 2.97 dan dalam skala (1-100) nilainya 74,22 sehingga masuk ke dalam kriteria baik. Berdasarkan hasil penilaian uji coba skala kecilyang dilakukan oleh siswa, aspek kemudahan mengakses informasi, aspek keaktifan, aspek pemahaman terhadap produk, aspek berani mengemukakan pendapat, dan aspek minat belajar termasuk dalam kategori baik. Setiap aspek memiliki jumlah rerata skor dengan kategori yang sama. Dan Penilaian uji coba skala besar yang dilaksanakan di SMAN 3 Yogyakarta dan SMAN 7 Yogyakarta ini memiliki penilaian produk dengan rerata skor sebesar 3,08 dan dalam skala (1-100) nilainya 77,02 sehingga masuk ke dalam kriteria baik. Berdasarkan hasil penilaian uji coba skala besar yang dilakukan oleh siswa, aspek kemudahan mengakses informasi, aspek keaktifan, aspek pemahaman terhadap produk, aspek berani mengemukakan pendapat, dan aspek minat belajar termasuk dalam kategori baik. Setiap aspek memiliki jumlah rerata skor dengan kategori yang sama.

\section{SIMPULAN}

Perkembangan pendidikan kontemporer saat ini mengalami banyak kemajuan termasuk dalam pembelajaran $e$ learning yang sangat berguna untuk memudahkan siswa dan guru dalam berinteraksi. Oleh karena itu, penelitian ini membuat media pembelajaran software yang dapat diakses melalui PC atau gawai. Berdasarkan hasil dari validasi ahli dan lembar validasi yang dinilai oleh siswa, secara keseluruhan produk software literasi digital berbasis media e-learning ini dinyatakan layak digunakan dalam proses pembelajran PJOK di tingkat SMA. Hal ini ditunjukkan dengan rerata skor penilaiannya yang masuk dalam kategori baik. 


\section{DAFTAR PUSTAKA}

Arikunto, S. (2011). Prosedur Penelitian Suatu Pendekatan Praktik. Jakarta : Rineka Cipta.

Abidin. (2017). Pembelajaran Literasi Strategi Meningkatkan Kemampuan Literasi Matematika, Sains, Membaca dan Menulis. Jakarta: Bumi Aksara.

Basoglu, D. (2018). The Importance of Physical Literacy for Physical Education and Recreation. Journal of Education and Training Studies, 6(4), 141.

Borg. (2007). Educational research an introduction (4th ed). New York: Longman Inc.

Lubis. (2015). Pengembangan Media Pembelajaran Kimia Berbasis Android Untuk Meningkatkan Motivasi Belajar Dan Prestasi Kognitif Peserta Didik SMA. Jurnal Inovasi Pendidikan IPA, 1(2), 191 201.

Noh, Y. (2017). A Study on The Effect Of Digital Literacy On Information Use
Behavior. Journal of Librarianship and Information Science 2017, 49(1), $26-56$.

Santoso, N. (2009). Pendidikan Jasmani di Sekolah Menengah Atas: Antara Harapan dan Kenyataan. Jurnal Pendidikan Jasmani Indonesia, 6(2), 2-3.

Sugiyono. (2017). Metode Penelitian dan Pengembangan. Bandung: Alfabeta.

Sukardjo. (2006). Kumpulan Materi Evaluasi Pembelajaran. Yogyakarta: Program Pascasarjana Universitas Negeri Yogyakarta.

Wahyhuningsih. (2017). E-Learning Teori dan Aplikasi. Bandung: Informatika Bandung.

Widiantoro, B., \& Rakhmawati, L. (2015). Pengembangan Media Pembelajaran E-Learning Berbasis Schoology Pada Kompetensi Dasar Memahami Model Atom Bahan Semi Konduktor di SMKN Negeri 1 Jetis Mojokerto. Jurnal Pendidikan Teknik Elektro, 4(2), 505-506. 